\title{
Algunas gestiones de mediación del Marqués de Villalobar durante la Primera Guerra Mundial
}

\author{
Álvaro lozano Cutanda

\begin{abstract}
Some mediation interventions done by the Villalobar Marquis during the First World War
\end{abstract}

\begin{abstract}
RESUMEN
En este artículo deseo recordar a una

figura de primer orden de la diplomacia española: Don Rodrigo Saavedra y Vinent, Marqués de Villalobar. Se trató de un personaje clave dentro la política exterior del

Rey Alfonso XIII. Su amistad y vinculos con la Corona, hicieron de él un defensor de la misma en sus puestos diplomáticos y encarnó como nadie la política exterior

que quiso llevar a cabo el Rey Alfonso XIII. El gran mérito del Embajador Villalobar fue el de superar una grave incapacidad física y con una gran fuerza de voluntad haber llegado a representar a España.

Esa sobrehumana superación personal, unida a su fuerte sentimiento monárquico, aristocrático y humanitario, fueron las constantes en su vida y su profesión.
\end{abstract}

PALABRAS CLAVE:

Primera Guerra Mundial. Rey Alfonso

XIII. Marqués de Villalobar, Neutralidad, Labor humanitaria, Diplomacia, Mediación.

\section{ABSTRACT}

In this article I would like to shed light on an outstanding Spanihs diplomat: Don Rodrigo Saavedra y Vinent, Marquis of Villalobar. He was a key figure in the foreign policy of King Alfonso XIII. His friendship and links with the Spanish royalty made him a strong supporter of the Crown in his diplomatic posts and he embodied like no one else the foreign policy of his King. The greatest merit of Ambassador Villalobar, was to overcome a big physical handicap, and through sheer will power, to become an ambassador. Without doubts, overcoming that handicap profoundly marked his personality during his entire life. That immense will power and his strong monarchic, aristocratic and humanitarian feelings, were the most outstanding features of his life and work.

KEYWORDS:

First World War. King Alfonso XIII, Marquis de Villalobar, Neutrality, Humanitarism, Diplomacy, Mediation. 


\section{INTRODUCCIÓN}

La Primera Guerra Mundial o la Gran Guerra, como fue llamada en su momento, supuso el fin de un mundo, y el comienzo de otro. Se considera así, de forma casi unánime, que el siglo xx comienza propiamente con el asesinato del Archiduque Francisco Fernando en 1914 y el comienzo de la Primera Guerra Mundial'. Como señala Ramón Barsuto: "conforme a las aportaciones realizadas por la reciente historiografía anglo norteamericana y alemana sobre el significado y la ubicación de los grandes fenómenos históricos dentro del marco de la Historia mundial contemporánea, o lo que sería lo mismo, de aquellos procesos de cambio de carácter decisivo, originadores de nuevas situaciones históricas, críticas e imprevisibles (turning points, wendepunkte) la Primera Guerra Mundial se nos presenta como la tragedia alumbradora de los tiempos modernos, tanto en Europa como en el resto del mundo, marcando el punto final de una época y el comienzo de nuevos desarrollos trascendentales"?.

Nuestro Embajador en Viena resumía lacónicamente en telegrama cifrado de 28 de junio aquel asesinato: "Archiduque Francisco Fernando y Esposa fueron asesinados en Serrayevo por anarquistas". ${ }^{3}$ Una cadena fatal de acontecimientos y de malas decisiones, cada una de las cuales no pretendía en si la guerra, o al menos su generalización, dio lugar a la mayor tragedia vivida por el mundo hasta entonces 4 .

Sus orígenes siguen siendo aún uno de los temas más controvertidos de la historiografía. El gran historiador Duroselle, tras una larga vida dedicada al estudio de las relaciones internacionales, declaraba antes de su fallecimiento que el origen de la guerra le resultaba finalmente incomprensible y, aunque hoy nos pueda resultar irónico, la primera causa mecánica de la Primera Guerra Mundial radicó en el hecho de que gran parte de los bosnios querian pertenecer al proyecto de la Gran Serbia. Pronto se sabria que los asesinos no eran anarquistas, sino nacionalistas bosnios ${ }^{5}$. El Rey de España envió enseguida sus condolencias al Empe-

1 Sobre el asesinato del archiduque y sus consecuencias véanse V. DeDIJER: La route de Sarajevo. Paris, 1969, y J. REMAK: Sarajevo. The story of a Political murder. Nueva York, 1969; G. BRook SHEPERD, Archduke of Sarajevo, The romance and tragedy of Franz Ferdinand of Austria, Boston-Toronto, 1984. Resulta también importante el ya clásico libro de viajes de R. WEST: Cordero Negro, Halcón Gris, Viaje al interior de Yugoslavia, Barcelona, 2000.

${ }^{2}$ Ramón BaRSuto, en J. Tusell, J. Avilés y otros: La Política exterior de España en el siglo xx, Madrid, 1997.

3 Archivo General del Palacio Real (en adelante AGP). Caja 15.252. Expediente 2. En adelante 15.252/2. Telegrama cifrado del embajador de España en Viena, Castro, al secretario particular del Rey, Torres, de 28 de junio de 1914.

${ }^{4}$ Sobre la influencia del tiempo en las gestiones diplomáticas de la crisis de julio de 1914 véase el capitulo titulado Temporality of the July Crisis, en S. KERN: The Culture of Time and Space. 1880-1918. Harvard, 1983, pp. 259-287 Véase también A. J. P. TAYLOR: War by timetable. Nueva York, 1969.

5 Sobre los últimos días del Imperio Austro-Húngaro, véanse F. MORTON: Thunder at Ttwilight, Viena 1913-1914, Cambridge, MA, 2001; F. FEJTO: Réquiem Pour un empire défunt, histoire de la destruction de L'Autriche-Hongrie, Paris, 1992, y A. SKED: The Decline and fall of the Habsgurg Empire 1815-1918, Londres, 2001. 
rador de Austria-Hungría, lo que era agradecido por el Embajador Imperial en Madrid: «Profundamente emocionado de las palabras (...) que Vuestra Majestad se ha dignado dirigir en su nombre y en el de Su Majestad La Reina con ocasión del terrible suceso que acaba de golpear de nuevo a su Majestad el Emperador y a mi patria. Mi más profunda gratitud y reconocimiento. Prinze Charles Emile de Feurstenmberg. Embajador de Austria-Hungría”6.

Uno de los primeros países europeos en sufrir la guerra fue Bélgica. Este país, cuya geografía ha sido calificada en la historia como «encrucijada de Occidente" o "corazón de Europa», fue el primer país cuya neutralidad fue violada al comienzo mismo de la Primera Guerra Mundial. Bélgica sufriría cincuenta meses de ocupación alemana. Los belgas creían en su neutralidad, en setenta y cinco años de independencia garantizada por las grandes potencias del momento, Bélgica había conocido el periodo más largo de paz de su historia. Anteriormente el territorio belga había servido de camino a invasores desde los tiempos de Julio $\mathrm{Ce}$ sar. Bélgica, a diferencia de otros países europeos, no decidió entrar en guerra, fue invadida porque "Alemania estimaba que las carreteras belgas llevaban a París como las venas conducen al corazón ${ }^{7}$. La única pregunta de su gobiemo era si resistir o no la invasión, y en caso de que lo hiciese, la forma de hacerlo. La política de Bélgica antes de la guerra había sido simple y clara: mantener al pais fuera de cualquier conflicto europeo, lo que conllevaba una posición política y militar ${ }^{8}$. La posición militar belga se basaba en la idea de la disuasión. Su principal objetivo era el de desanimar a cualquier posible agresor, mostrándole el alto precio que pagaría por la invasión. Sin embargo, un simple análisis geográfico de Bélgica les hacía prepararse para lo peor.

Una vez declarada la guerra, España adoptó enseguida una política de estricta neutralidad y ofreció encargarse de la protección de los intereses belgas, lo que dio ocasión a una extraordinaria gestión diplomática y humanitaria de nuestro ministro y posterior embajador en Bruselas, el Marqués de Villalobar. La estrecha relación existente entre las dos casas reales y el papel personal ejercido por el rey Alfonso XIII, se transformó en una muy fructífera labor humanitaria española9. Esta labor de auxilio a una nación devastada por la guerra fue, en muchos aspectos, precursora de la ayuda humanitaria que realizan hoy en día las tropas españolas destacadas en conflictos como el de la antigua Yugoslavia y Afganistán, entre otros.

6 AGP. 15.252/ 2. Carta del Embajador de Austria-Hungría en Madrid. Julio de 1914.

7 L. ZUCKERMAN: The rape of Belgium, Nueva York. 2004, p. 1.

${ }^{8}$ Véase K. Wilson (ed.): Decisions for war, 1914, Nueva York, 1995, pp. 151-175.

9 La labor de mediación sobre Prisioneros belgas se encuentra recogida en el Archivo General de Palacio junto con los heridos y prisioneros franceses en las cajas 50 a 418 . Expedientes 1 al 111.870, dato que sirve de testimonio de la inmensa labor de mediación y de búsqueda de Prisioneros que realizó la Oficina Pro Captivis del Palacio Real. 


\section{EL MARQUÉS DE VILLALOBAR}

La carrera diplomática en la época de Alfonso XIII estaba marcada por la falta de un sistema objetivo en el ingreso a la misma y en el posterior nombramiento de embajadores. Era una carrera en la que destacaban los aristócratas y las grandes fortunas, aunque la mayor parte del personal diplomático puede afirmarse que correspondía a la alta burguesía ${ }^{10}$. A pesar de tratarse de un cuerpo no totalmente profesional, durante el trágico conflicto la carrera diplomática española contó con excepcionales embajadores. Los más importantes y destacados durante la contienda fueron Ramírez de Villaurrutia en París desde 1913, de tendencia francófila; en Londres, Alfonso Merry del Val y Zulueta, anglófilo; Polo de Bernabé y Pilón, en Berlín desde 1906; en Roma desde 1911, Ramón Piña y Millet, a la cabeza de una complicada embajada ya que no eran buenas las relaciones entre los Saboya y los Borbones ${ }^{11}$. En San Petersburgo, desde marzo de 1914, se encontraba Aníbal Morillo y Pérez, Conde de Cartagena; en Berna, Francisco de Reynoso, y en Lisboa desde mayo de 1913, el Marqués de Villasinda, Luis Valera y Delavat. Por último, dentro de los diplomáticos que jugarian un papel importante durante la guerra, se encontraba Cipriano Muñoz y Manzano, Conde de la Viñaza, en el Vaticano. Alfonso XIII siempre consideraría prioritarias las relaciones con la Santa Sede ${ }^{12}$. El titular de la cartera de Estado era, desde octubre de 1913, Salvador Bermúdez de Castro y O'Lawlor, Marqués de Lema y Duque de Ripalda.

Otra personalidad destacada del periodo fue el jefe de la Secretaría Particular del Rey Alfonso XIII, el Marqués de Torres Mendoza, Emilio María de Torres y González Arnao. El Marqués de Torres Mendoza se convirtió en el "hombro del Rey» en la difícil y enorme tarea que asumió Alfonso XIII durante la guerra ${ }^{13}$. Emilio de Torres ingresó joven en la carrera diplomática, en la cual sería destinado a Berlín en 1898, a Estocolmo en 1899, ocupando también diversos puestos en el Ministerio de Estado, hasta que fue enviado de nuevo al exterior, a Berlín, en 1901. Su conocimiento de Alemania le fue de gran utilidad durante la guerra. En 1909 fue nombrado secretario particular de Alfonso XIII. En mayo de 1914, fue destinado a Tánger, puesto de vital importancia para el africanismo español ${ }^{14}$. Con el inicio de las hostilidades en Europa, Torres regresó a su puesto de secretario particular del Rey Alfonso XIII y jefe de la Secretaría de la Oficina Pro Captivis del Palacio Real de Madrid. Fue un gran gestor, y su cargo se convirtió durante la guerra en un segundo ministro de Estado. Hombre de firmes convicciones, trabajador infatigable y muy responsable, fue una pieza fundamental de la obra humanitaria del Rey ${ }^{15}$.

10 R. VAldivieso del ReAl: La carrera diplomática en España (1939-1990), Madrid, 1996, p. 26.

11 J. PANDo DesPIerto: Un Rey Para la esperanza. La España Humanitaria de Alfonso XIII, Madrid, 2002 , p. 39.

12 C. Seco Serrano: Viñetas Históricas, Madrid, 1983, pp. 313-318.

13 J. Pando Despierto, ob. cit., p. 40.

14 Archivo del Ministerio de Asuntos Exteriores (en adelante AMAE). Expedientes Personales Legajo $61 / 2547$ (en adelante $61 / 2547$ ).

15 J. PANDo Despierto, ob. cit., p. 41. 
De entre todos los embajadores que sirvieron a España durante la Primera Guerra Mundial, uno de ellos brilló especialmente. Se trata del Marqués de Villalobar, Rodrigo de Saavedra y Vinent. Hombre de gran personalidad, inteligente y de férrea voluntad, trabajador infatigable, manifestó durante su misión en Bélgica una gran capacidad humanitaria, llegándose a convertir en un verdadero protector de los belgas. Rodrigo de Saavedra nació en Madrid en 1866 y murió en Bruselas, siendo embajador de España, en julio de 1926. Ingresó muy joven en la carrera diplomática y desempeñó diversos cargos en París, Washington, Londres y Lisboa. En éste último puesto coincidió con la caída de la monarquía portuguesa, donde manifestó su inclinación monárquica ${ }^{16}$.

El Barón Von der Lancken, encargado alemán de la Sección Política en la Bélgica ocupada, escribió en sus memorias elogiosas palabras hacia Villalobar: «EI Ministro de España era el Marqués de Villalobar. ¡Personalidad sorprendente! Dedicado a su trabajo en una larga carrera diplomática, muy inteligente y muy fino, lleno de iniciativas y desbordante de una fuerza creadora infatigable, dotado de una admirable energía física que le permitía superar una grave incapacidad natural, la ausencia de sus miembros inferiores. De naturaleza amable y previsora, pero refinada, a menudo demasiado generoso en la elección de los medios, asi era Villalobar, que jugó un papel como ningún otro de sus colegas en Bruselas (...) Es posible que su ardiente ambición y la esperanza de tener un papel político también contribuyesen, pero a fin de cuentas, no teníamos por qué quejarnos. Con gran tacto y destreza resolvió dificultades que surgían aquí y allá" "17.

En sus memorias sobre la guerra, Belgium a personal narrative, el entonces embajador de Estados Unidos en Bélgica, Brand Whitlock, recordaba su relación con Villalobar: «...Bajo una apariencia de orgullo, era un hombre sensible, lleno de recursos y absolutamente sin miedo. ¡ $Y$ de que manera se comportaba con los alemanes, que no conocen a iguales, sólo superiores e inferiores...!» ${ }^{18}$. En 1926 Brand Whitlock le recordaba tras su muerte: «su muerte me entristeció, ya que fuimos buenos amigos. Nuestra amistad comenzó en América donde era Ministro en Washington y nuestra experiencia en Bruselas durante la guerra, nos acercó muchísimo. Era un hombre notable, de una extraordinaria personalidad, lleno de sorprendentes contradicciones (...) a pesar de sus ideas monárquicas (...) era un hombre realista y muy demócrata (...) Admiraba las instituciones anglosajonas. Gozaba de una energía inacabable y una voluntad de hierro, cuidaba minuciosamente cada detalle del trabajo de la embajada y trabajaba hasta altas horas de la madrugada, y pronto por la mañana (...) Tenían que haberle visto tratar con los alemanes: "Hable despacio, educadamente y en francés" le ordenó un día al jefe de la

\footnotetext{
${ }^{16}$ Archivo Real Academia de la Historia. (ARAH). Archivo Natalio Rivas. Recortes de Prensa de la Revolución Portuguesa de 1910,11/8892. Véase también el libro del gran especialista en las relaciones hispano-portuguesas, HIPÓLITO DE LA TORRE: El Imperio del Rey, Alfonso XIII, Portugal y los ingleses (1907-1916), Mérida, 2002, pp. 82 y ss.

17 B. VON DER LANCKEN: Mémoires, Paris, 1932, pp. 140 y 142.

18 B. WHITLOCK: Belgium a Personal narrative, Nueva York, 1919, p. 240.
} 
policía secreta alemana (...) El mundo es hoy un poco peor $\sin$ el ${ }^{19}$. En el diario de Brand Whitlock, editado por Allan Nevins y publicado en 1936, Whitlock no ahorraba elogios hacia Villalobar: "Villalobar es excelente, el mejor y el más amable de los hombres" ${ }^{20}$.

¿Cuál era la actitud personal de Villalobar hacia Alemania? El Barón Von der Lancken se hacía esta misma pregunta en sus memorias: "para responder a esta pregunta, algo nada fácil, es necesario tener en mente lo siguiente. Durante largos años, Villalobar había sido consejero de la Embajada en Londres. Había pertenecido a los círculos más próximos del Rey Eduardo VII y entre sus amigos se encontraban numerosos miembros influyentes de la aristocracia inglesa. Hacia el Rey de Bélgica sentía una verdadera veneración, y en la Corte de Bruselas se le consideraba como un huésped muy respetado. Los intereses que representaba le ligaban a Francia bajo múltiples aspectos. Por lo tanto, en cuanto a lo meramente sentimental, se encontraba unido por fuertes vínculos a los países de la Entente. Pero Villalobar era ante todo español, y un fervoroso monárquico. El no veía la guerra más que desde el punto de vista de la España monárquica»21.

Según el Barón Beyens, hijo del que fuera Ministro belga de Asuntos Exteriores, «...Villalobar era un aristócrata puro, y un monárquico convencido. El ascenso del socialismo le preocupaba. Veía claramente el peligro que para la Dinastía Hohenzollern tendría una victoria decisiva de los Aliados, y de rebote para el resto de las coronas europeas, incluida la española. En fin, no veía con buenos ojos la entrada en guerra de los Estados Unidos, temiendo que expandiesen sobre el viejo continente las ideas democráticas que llevarian a la ruina a los regímenes como el que existía en su país. Estos temores, así como sus fuertes sentimientos humanitarios, le convertían en defensor de una paz de compromiso, sin vencedores ni vencidos (...) de ahí también su tendencia a juzgar las propuestas de paz alemanas como dignas de ser tomadas en consideración incluso, cuando en el fondo de su corazón, debía como hombre clarividente que era, reconocer la falta de consistencia y de sinceridad de las mismas. Había que firmar la paz de forma inmediata, esa era la frase constante de sus cartas, sino todo estará perdido» ${ }^{22}$.

Según Von der Lancken, «debía pensar que los intereses de España y del trono de su Rey se encontrarian más seguros al lado del poderoso Imperio Alemán, que en manos de las democracias occidentales. La espina que suponía Gibraltar, así como el recuerdo de 1898 , le motivaban a ir en contra de Inglaterra. A todo esto se le unía, una verdadera admiración por el Káiser y por el ejército alemán. Su ambición personal era ser destinado más tarde, una vez que hubiese terminado la guerra con un triunfo alemán, como embajador en Berlín. Villalobar contaba con

19 The Spectator, 11 de septiembre de 1926.

20 A. Nevins (ed.): The Journal of Brand Whitlock, Nueva York, p. 65.

21 B. VON DER LANCKEN, ob. cit., p. 142.

22 B. BEYENS: Un diplomate belge au service de son Pays. 1915-1917, Bruselas, 1981, pp. 119-120. 
una excelente red de contactos entre la población belga. Está fuera de toda duda que Villalobar deseaba ese fin para la guerra, ya que favorecia los intereses de su propio país" ${ }^{23}$. Sin embargo, esta actitud percibida por Von der Lancken no se deduce de su comportamiento durante la ocupación alemana. Villalobar actuó en todo momento con profesionalidad y como un gran defensor de los intereses belgas. Lo que si era cierto es que, como ferviente monárquico, Villalobar temia que una victoria aliada fuese el fin de las monarquías europeas ${ }^{24}$.

Como señala el historiador Jacques Villequet, "ocultaba bajo la apariencia de una infatigable amabilidad, dispuesto a servir a los demás, una personalidad muy fuerte, enérgica, voluntaria y sin duda ambiciosa. Su inteligencia, y su astucia le permitían dejar a sus interlocutores sin saber sus verdaderos sentimientos. Es significativo de ello, que en sus Memorias, el Barón Von der Lancken, de hecho su amigo íntimo, persistiese en la creencia de que Villalobar deseaba una victoria alemana en la Primera Guerra. Jules Chambón, que le conocía bien, respondía a la pretendida germanofilia y aseguraba que si Villalobar deseó en algún momento una victoria, esa no podía ser otra que la de Inglaterra, país por el cual sentía una verdadera admiración" ${ }^{25}$. "Era ante todo un gran señor, patriota y absolutamente dedicado a su soberano. Para nosotros, los belgas, él será siempre el diplomático, que según la feliz expresión de su sucesor, transformó su legación en un «Ministerio del Derecho y de la Generosidad", "Tutor de los belgas oprimidos", "la viva imagen de la misericordia». Villalobar utilizó durante cuatro años su gran prestigio con los alemanes para obtener medidas menos duras, conseguir indultos y proteger a nuestras poblaciones infelices.

En cada momento doloroso de la ocupación, su nombre aparecía como el de un conciliador o de un intermediario a menudo apreciado por los mismos alemanes: huelga de tribunales, deportaciones de obreros, ejecución de la señora Cavell, etc. En fin, en 1918, protección de nuestras fabricas y obras de arte. Por otra parte, se dedicó en cuerpo y alma a la protección y la gestión de los intereses franceses, italianos, brasileños, japoneses, portugueses, rumanos, serbios, rusos y finalmente americanos. Junto con el apoyo del embajador Brand Whitlock, dedicó toda su energía al Comité Nacional de Socorros y Alimentación ${ }^{26}$. Según el Barón Beyens, la infatigable actividad de Villalobar, se desarrolló principalmente en dos direcciones: como Alto Protector de la Commission for Relief in Belgium, y como mediador salvando a numerosas personas de ser fusiladas. Sus cartas con el Barón Beyens, son prueba de su preocupación constante por asegurar a la población belga, amenazada por el hambre, un abastecimiento suficiente ${ }^{27}$. Como se-

23 B. VON DER LANCKEN, ob. cit., p. 141.

24 Entrevista personal con Carlos SaAvedra, hijo del Marqués de Villalobar. Noviembre 2003 (fallecido en mayo de 2004).

${ }^{25}$ Archivo Familia Villalobar (en adelante AFV) 5/1917. Documentos relativos a la Commission for Relief in Belgium.

26 AFV. 22/1916. Documentos relativos a la Commission for Relief in Belgium.

27 AFV. 23/1916. Cartas entre el Barón Beyens y el Marqués de Villalobar. 
ñala el hijo del Barón Beyens, "su actividad en este terreno merece los mayores elogios" ${ }^{28}$.

El inicio de las labores de mediación del Rey Alfonso XII se sitúa en agosto de 1915, cuando una francesa le pidió al Rey que hiciera gestiones acerca del paradero de su marido, que acabó apareciendo en un campo de concentración alemán. Posteriormente, se creó una oficina que dependiente del Rey, alcanzó a tener a cuarenta personas a su cargo. La gestión humanitaria abarcó los más distintos aspectos. Llegó a haber más de diez secciones que abarcaban diversos aspectos de la guerra: indultos, prisioneros, desaparecidos, etc. Se logró más de un centenar de indultos de penas contra reos, algunos de ellos españoles, que habían sido acusados de espionaje ${ }^{29}$.

En los primeros días de julio de 1915, la correspondencia alcanzó niveles inusuales en una dirección del correo español, el Palacio Real de Madrid. Durante los años 1915-1916, en los que el departamento tuvo mayor actividad, llegaron hasta 20.000 cartas al mes en demanda de ayuda. Hasta medio millón de documentos fueron recibidos o enviados desde el Palacio de Oriente ${ }^{30}$. La mayoría de las cartas, escritas en francés, llevaban como señas: «Sa Majesté le Roi Alphonse XIII, Palais Royal, Madrid." Tenian un denominador común: pedir noticias sobre militares prisioneros o desaparecidos, pero también refugiados o rehenes civiles, internos en campos de concentración. Su destinatario era el único jefe de Estado comprometido en tal asistencia, informativa y moral. Dirigir en aquel momento trágico una carta al Palacio Real era dirigir una carta a la esperanza ${ }^{31}$. Cuando concluyó la Guerra Mundial, Alfonso XIII comenzó a ser objeto de duros ataques, pero al Rey le quedaba el resultado de su acción humanitaria en años precedentes.

\section{LOS CASOS DE LOS PROFESORES HENRY PIRENNE Y PAUL FRÉDERICQ}

En abril de 1916, el redactor en jefe del periódico El Universo abogaba en un artículo por la intervención de España a favor de dos belgas, los catedráticos Henri Pirenne y Paul Frédéricq, los cuales habían sido deportados a Alemania e internados en uno de los campos de concentración más duros de Alemania, Holzminden. En el artículo se destacaba «la altura intelectual de ambos profesores y su marcado hispanismo", especialmente en el caso de Henri Pirenne, por haber escrito dos tomos de su Histoire de Belgique, "esclareciendo favorablemente la his-

${ }^{28}$ B. BeYENS, ob. cit., p. 118.

29 J. TUSELL y G. QUeIPO DE Llano: Alfonso XIII, El Rey Polémico, Madrid, 2002, p. 300.

30 Idem, p. 301.

${ }^{31}$ Un amplio estudio de todas las gestiones humanitarias del rey Alfonso XIII en J. PANDO DESPIERTO: Un Rey Para la esperanza. La España humanitaria de Alfonso XIII en la Gran Guerra. Madrid. 2002. Véanse también J. CORTES-CavanilLAs, Alfonso XIII y la Guerra del 14. Madrid, 1976 y Espinós Moltós, Alfonso XIII Espejo de Neutrales, Madrid, 1977. 
toria de los españoles en dicha nación ${ }^{32}$. Henri Pirenne, había consolidado en Bélgica la historia económica y social con sus trabajos sobre el origen mercantil del Renacimiento urbano medieval (Las ciudades de la Edad Media de 1927) y sobre la ruptura de la unidad mediterránea clásica en el siglo vill bajo el impacto de la expansión musulmana. (Mahoma y Carlomagno) ${ }^{33}$. Henri Pirenne nació el 23 de diciembre de 1862, hijo de un industrial de la localidad de Verviers. Realizó sus estudios en la Universidad de Lieja donde tuvo como profesores a Paul Frédéricq y a Godefroid Kurth, que le iniciaron en la historia. Obtuvo su doctorado en Filosofía y Letras el 6 de julio de 1883. Completó su formación en Leipzig y Berlín (1883-1884) y posteriormente en Paris. Con 22 años fue nombrado encargado de estudios en la Universidad de Lieja.

El año siguiente fue nombrado profesor en Gante con el rango de profesor extraordinario y enseñó en esta ciudad hasta 1929. Sus intereses versaban sobre el problema de los orígenes urbanos y la decadencia occidental en la Alta Edad Media. En cuanto a la historia nacional belga, su monumental obra Histoire de Belgique le valió el reconocimiento general. Esta historia de Bélgica respondía al pedido del historiador alemán Karl Lamprecht. Según Pirenne, Bélgica no era un estado nuevo, sino que su creación se remontaba al Tratado de Verdún de 843, existía desde la Edad Media un pueblo belga caracterizado por una civilización común, a la vez romana y germánica. El Estado belga creado en 1830 , según Pirenne, era una necesidad histórica. Desde 1900 la obra se convierte en una verdadera Biblia para los nacionalistas.

El redactor de El Universo escribió personalmente al secretario del Rey pidiéndole su intervención en favor de los citados ilustres profesores: «Mi respetado señor, suplico a V. que se fije en el articulo que publica El Universo de hoy en primera plana, con el título: "Dos nuevas victimas de la guerra", y si lo juzgase oportuno, que se digne llamar la atención de nuestro querido y generoso Soberano, no sobre el artículo sino sobre su contenido, pues, a mi humilde juicio entra de lleno esa suplica en la bonisima obra que Su Majestad (S.D.G) realiza en estos momentos con tanta gloria suya y por tanto, de la Patria. Sólo el intentarlo seria gloriosísimo para el Rey y para España. Perdone el atrevimiento si lo juzga impertinente y mande como guste a su agradecido y afectísimo. Ángel Salcedo. 12 de abril de $1916{ }^{34}$.

El secretario personal del Rey le contestó: «Mi distinguido amigo: Tan pronto como recibí su amable carta me apresuré a darla a conocer a S.M. el Rey, y me es muy grato decir a $V$. que nuestro Augusto Soberano, cuando llegó su misiva a sus reales manos, había leído ya el interesante artículo publicado por V. en El Universo de ayer. S.M. el Rey se ha dignado a prestar la más favorable acogida al caso Pirenne y ha tenido a bien recomendar, con el mayor interés, a Su Embajador en

32 El Universo, 12 de abril de 1916.

33 EnNSt BreisaCh: Historiography: Ancient, Medieval \& Modem, Chicago, 1994, p. 357.

${ }^{34}$ AGP. OPC. Expedientes 544 y 548. 
Berlín y al Ministro de España en Bruselas (Villalobar) que procuren conseguir de las autoridades alemanas el perdón de ambos profesores...». Villalobar utilizó todos sus contactos para conseguir la liberación de los dos profesores, en especial su buena relación con Von der Lancken. La gran cantidad de gestiones y la presión que pudo realizar por su buena reputación entre las fuerzas de ocupación dieron pronto sus frutos ${ }^{35}$.

Al mismo tiempo, el Embajador de España en Berlín, se interesó de inmediato por la suerte de los dos profesores, de lo que daba cuenta al secretario personal del Rey: «Mi querido amigo y compañero: en respuesta a su carta de fecha 13 de abril, tengo el gusto de participarle que he hecho acerca de estas autoridades, las gestiones oportunas a fin de tratar de conseguir el indulto, o en caso negativo, mejorar la suerte de los señores Frédéricq y Pirenne, por quienes se interesa tanto S.M. El Rey, por haber dado muestras de afecto a España en momentos en que en el extranjero, (crisis de 1909) se hacía contra ella una campaña sectaria. Tan pronto como obtenga una respuesta me apresuraré a ponerla en su conocimiento. Queda de V. buen amigo y compañero" ${ }^{36}$. Se abrieron en Palacio dos expedientes al respecto, expedientes de Repatriación Civil, los números 547 (Paul Frédéricq), y 548 (Henri Pirenne) ${ }^{37}$.

El propio Rey Alberto I solicitaba la mediación de nuestro Rey para salvar a los eminentes profesores belgas, en carta autógrafa fechada en La Panne, el 25 de abril de 1916: "La gran simpatía que has demostrado por mi país y tu alta solicitud para tantos belgas que se encontraban en situaciones difíciles me animan a pedirte un favor. El Profesor Pirenne de Gante, nuestro mejor historiador y un excelente patriota, acaba de ser encarcelado en Alemania. Si crees que puedes hacer algo por él, por ejemplo, que pueda ser enviado a un país neutral, Suiza o cualquier otro, te estaría personalmente agradecido si consintieras mediar por la libertad de Mr. Pirenne, que es un anciano para el que una larga estancia en prisión podría ser fatal. Somos particularmente felices de ver por aquí al Marqués de Villalobar, un verdadero amigo para nosotros..." ${ }^{38}$.

El Rey Alfonso XIII contestaba desde San Sebastián a los Reyes de Bélgica: "Acabo de recibir tu carta y me voy a ocupar inmediatamente de ello. Será una alegría poder conseguirlo, a ti y a la Reina, mis afectuosos recuerdos. Alfonso $\mathrm{R}^{3{ }^{39}}$. En telegrama enviado a Berlín, el rey Alfonso XIII por medio de su secretario personal se hacia cargo de la situación de los dos profesores belgas: «S.M. tiene particular interés en V.E obtenga del que el profesor de Gante, Pirenne, sea internado en Suiza.". Un mes después, Torres comunicaba al embajador de Bélgica en

${ }^{35}$ AFV. Documentos Relativos a los Profesores Henry Pirenne y Paul Frédéricq.

36 AGP. OPC, caja 53. Expediente 547. carta del Embajador de España en Berlín Polo de Bernabé a don Emilio M. de Torres.

${ }^{37}$ J. PANDO DESPIERTO, ob. cit., p. 366.

38 AGP. OPC, caja 53. Torres a Ángel Salcedo, 13 de abril de 1916.

39 AGP. OPC, caja 53. Expediente 548. Carta del Rey Alfonso XIII a los Reyes de Bélgica. Hotel Maria Cristina. San Sebastián 3 de mayo de 1916. 
Madrid, el Barón de Grenier, las buenas expectativas que parecían darse en el caso de los profesores. El barón no tardó en contestar: «No puedo concebir que las autoridades alemanas se permitan vulnerar la demanda que, en derecho, Su Majestad el Rey se ha dignado realizar a favor de mis compatriotas, con la generosidad que en él es habitual» ${ }^{40}$.

El hijo de Henri Pirenne hacia una súplica a los Reyes de España para que se interesaran por la suerte de su padre: "su hijo suplica a Su Majestad el Rey de España que intervenga una vez más en su favor. Su Majestad ha aliviado su suerte con ocasión de su arresto y su hijo suplica a Su Majestad que se interese de nuevo a favor del insigne historiador y escritor belga. Su liberación o su traslado a Suiza es urgente. Las últimas noticias recibidas a propósito de él son cada vez más preocupantes. Su dirección es: Henry Pirenne. Creuzberg cerca de Eisenach en Thuringia en el albergue "Zum Stern". Su número de prisionero es: Belgische Kriegsgefangen n. ${ }^{\circ}$ 10820. Responder a Jacques Pirenne. Villa des Glyeines. Mers su Mer ${ }^{41}$.

La legación de Bélgica en España agradecía las gestiones a favor de los dos profesores desterrados en carta de 5 de junio de 1916: «muy señor mío: me llena de alegría enterarme de la buena noticia que muy amablemente tuvisteis las delicadeza de trasladarme ayer, sobre los señores Pirenne y Frédéricq. No dudo que las autoridades alemanas hayan cursado la petición que Su Majestad El Rey se tomó la molestia de hacer a favor de nuestros compatriotas con la generosidad que le caracteriza. Os ruego le hagáis llegar a Su Majestad la expresión de mi profunda gratitud y respeto hacia esta nueva prueba de Su inmensa bondad con los belgas... ${ }^{42}$ Nuestro embajador en Berlín pudo dar la buena noticia de la mejora de la situación de los dos profesores: «Amplío mis telegramas de ayer referente profesores Pirenne y Frédéricq. Acabo recibir nota comunicándome, oficialmente, que dichos señores han sido trasladados, el 28 de agosto y el 8 de septiembre, respectivamente a Jena, donde disfrutan de completa libertad y tienen facilidad de estar en aquella Universidad " ${ }^{43}$.

De esta forma, dos hitos de la historiografía europea pudieron ver la luz gracias a la ayuda española, tras pasar por las estrecheces del campo de Holzminden y el confinamiento de Creuzburg (Turingia). En la introducción al libro Mahoma y Carlomagno, su hijo Jacques no cita la labor realizada por Villalobar para su liberación, dando tan sólo el dato de su paso por el campo de concentración alemán y su labor en el mismo ${ }^{44}$. En diciembre de 1917 regresaban a Bruselas los deportados belgas en Alemania: “Ayer regresaron á Bruselas todos los deportados belgas de-

40 AGP, OPC, caja 53. Grenier a Torres, Madrid 5 de junio de 1916.

${ }^{41}$ AGP. OPC, caja 53. Expediente 548. carta de Jacques Pirenne al Rey Alfonso XIII. (No consta la fecha exacta.)

42 AGP, OPC. Caja 53. Expediente 548. Carta de la legación belga en Madrid al secretario particular del Rey, de 5 de junio de 1916.

43 Ibidem.

44 Introducción al libro de HenRY PIRENnE: Mahoma y Carlomagno, Madrid, 2003, p. 9. 
tenidos en Alemania como rehenes libertados merced a gestión S.M. el Rey. Solicito y ruego á V.E. se sirva elevar á nuestro Augusto Soberano expresión de su más profundo agradecimiento por beneficio que le deben y respetuoso homenaje á su Real Persona. Villalobar ${ }^{45}$.

\section{EL CASO DE LA ENFERMERA EDITH CAVELL.}

Desde la ejecución del Duque D'Enghien por órdenes de Napoleón, ningún fusilamiento había causado en el mundo una impresión tan fuerte como el de la enfermera Edith Cavell, uno de los personajes más fascinantes de la Primera Guerra Mundia ${ }^{46}$. Su padre había sido un estricto vicario victoriano. Cavell trabajó primero como gobernanta para la familia François en Bélgica. En 1895 su padre enfermó gravemente y Edith regresó de urgencia a Inglaterra para ocuparse de él. La experiencia le hizo ingresar en la Escuela de Enfermeras de Londres. Después de completar el curso, continuó en el hospital como enfermera privada y en 1910 se convirtió en supervisora de noche. En ese periodo de tiempo Antoine Depage, brillante cirujano belga, se encontraba muy frustrado por las órdenes religiosas que controlaban a las enfermeras en Bélgica. Quería transformar el sistema con profesionales, sistema desarrollado por Florence Nightingale en Inglaterra. Deseaba así, desarrollar esta nueva profesión en Bélgica con enfermeras profesionales, y crear al mismo tiempo una carrera para las jóvenes belgas de buena educación ${ }^{47}$.

Propuso comenzar la tarea con una escuela para enfermeras en el Instituto Berkendael, donde él trabajaba. Para llevar a buen puerto el proyecto, buscó una matrona que tuviese experiencia administrativa, facilidad para la enseñanza y que hablase francés. También deseaba a alguien que hubiese sido entrenada en las formas de la Escuela de Florence Nightingale. Edith Cavell era la persona más indicada para el puesto y abrió la escuela el 1 de octubre de 1907. Como consecuencia de su gran dedicación y trabajo, enseguida aumentó el nivel profesional de las enfermeras belgas y las solicitudes se incrementaban sin cesar. En 1911, ya estaba entrenando enfermeras para tres hospitales, 24 escuelas y 13 guarderías en Bélgica. Era una persona estricta pero de gran corazón. Su sentido del deber «bordeaba el fanatismo" ${ }^{48}$.

En agosto de 1914, Cavell disfrutaba de unas cortas vacaciones en Inglaterra junto a su madre, que entonces vivía en Norwich tras el fallecimiento de su marido. En cuanto recibió las dramáticas noticias de la invasión alemana de Bélgica, le dijo

45 AMAE. H3040/10. Telegrama cifrado n. ${ }^{\circ} 227$. El ministro de España al ministro de Estado. La Haya, 20 de diciembre de 1917.

${ }_{46}$ Sobre la vida de Edith Cavell véanse: J. ELKoN: Edith Cavell, Heroic Nurse; Nueva York, 1979; Sally Grant: Edith Cavelt, E. GreY: Friend within the gates: The Story of Nurse Edith Cavell, Boston, 1971.

47 A. UnGER: revista British Heritage, mayo 1997.

48 lbidem. 
a su madre: «me necesitan en el Continente" antes de partir hacia Bélgica ${ }^{49}$. Su madre no la volvió a ver. Al ser invadida Bélgica, los alemanes ofrecieron a Edith Cavell un salvoconducto para salir hacia Holanda junto con el resto de las enfermeras. Cavell y algunas de sus ayudantes se negaron y permanecieron en Bruselas. Cavell y su equipo comenzaron su tarea de curación y asistencia a los numerosos heridos que llegaban de los campos de batalla. Enfermeras alemanas reemplazaron a las inglesas, sólo Edith Cavell y alguna colaboradora cercana consiguieron permanecer en sus puestos. En noviembre de 1914, dos soldados británicos vestidos de civil fueron conducidos por las desérticas calles de la Bruselas ocupada, guiados por un ciudadano belga, Herman Capiau ${ }^{50}$. Capiau, ingeniero de profesión, se había dedicado desde el comienzo de las hostilidades a colaborar con una red de escape para soldados franceses y británicos, atrapados tras las líneas alemanas. Las patrullas alemanas eran frecuentes, y a su paso fusilaban a todos aquellos soldados ocultos y a las personas que los acogían. Capiau tuvo que intentar tres caminos antes de poder alcanzar el Instituto Berkendael a las afueras de la capital belga.

Una vez allí, los tres fueron admitidos en el centro. Era algo totalmente contrario a la naturaleza de Cavell el rechazar la ayuda a dos hombres en peligro: «estos hombres son fugitivos" señaló a la hermana White, una enfermera inglesa que había permanecido en el centro, "hay que proporcionarles camas...". Los dos soldados británicos, el teniente coronel Dudley Boger y el sargento mayor Frank Meachin fueron ocultados en el Instituto durante dos semanas. Serían los primeros de más de 200 soldados británicos, franceses y belgas que fueron tratados y ocultados por Edith Cavell y su personal en doce meses. Cada día llegaban más y más soldados al centro y todos recibian ayuda de Edith Cavell. Sin embargo, el peligro de que los alemanes descubrieran el secreto aumentaba con el paso de los días. Los soldados británicos ocultos tenían prohibido salir al exterior. A pesar de ello, varios soldados se emborracharon y poco tiempo después era ampliamente conocido el hecho de que Cavell albergaba tropas británicas y francesas en el Instituto. A pesar de una orden alemana tajante de que cualquier ciudadano que estuviese albergando tropas aliadas sería fusilado en el acto, el trabajo secreto de Cavell continuó.

Era obvio sin embargo, que la ruta de escape hacia países neutrales no iba a permanecer abierta mucho tiempo. Los alemanes eran plenamente conscientes de que grandes números de tropas estaban cruzando la frontera holandesa. En agosto de 1915, los alemanes entraron en la casa de Philippe Baucq, un miembro de una organización de escape de soldados aliados. Baucq fue detenido, y gran parte de su documentación incautada. En ella constaban diversas cartas incriminatorias de Edith Cavell. El jefe de la organización de escape era el Principe de Croy, que en cuanto supo del arresto de Baucq advirtió a sus colegas en Bruselas. Llamó a Cavell y le avisó que él se escondería a partir de ese momento. La respuesta de

49 A. E. Clafk-Kennedy: Edith Cavell: Pioneer and Patriot, Londres, 1965.

50 Vease I. VINTON: The story of Edith Cavell, Londres, 1960. 
Cavell fue firme: «Espero ser arrestada (...) el escape en mi caso es inútil e impensable». El príncipe de Croy se dio cuenta de la imposibilidad de convencer a Cavell y partió hacia la frontera holandesa.

El 5 de agosto Otto Mayer, de la policía secreta alemana, se presentó en el centro. Cavell fue conducida a la jefatura de policía e interrogada. Sin embargo, nada de importancia fue encontrado en el Instituto, Cavell había escondido su diario en un almohadón. Existe una gran controversia sobre las declaraciones que $\mathrm{Ca}$ vell realizó a Otto Mayer. Cuando se le dijo que otros miembros de la organización habian admitido su culpa, ella declaró abiertamente sobre su papel de ayuda a los soldados aliados: "de no haberles ayudado", declaró, "habrían sido fusilados". Cavell fue acusada formalmente de conducir a soldados aliados hasta las líneas enemigas y fue juzgada por un tribunal militar en Bruselas. A pesar de la cantidad de soldados que habían sido ocultados por Edith Cavell, la única prueba incriminatoria fue una desgastada tarjeta postal enviada por un soldado agradecido. Cavell fue condenada a muerte, junto con cuatro ciudadanos belgas.

Para nuestro representante en Bruselas se iniciaba una frenética actividad intentando evitar el fusilamiento de la enfermera inglesa. Es muy probable que de haber tenido conocimiento inmediato de la posible ejecución de Cavell, el marqués de Villalobar hubiese podido interceder con más tiempo en su causa y Cavell se hubiese salvado. El Barón Von der Lancken narra así en sus memorias el momento en que tuvo conocimiento de la detención de Cavell: «...la tarde del 11 de octubre de 1915, me encontraba en un teatro de Bruselas cuando me anunciaron que el Embajador español, Marqués de Villalobar, decano del cuerpo diplomático, me esperaba en mi residencia, en compañía del consejero de la Legación americana Gibson y del abogado belga de esa representación Leval, para hablarme de un asunto de suma gravedad. Ignorando completamente lo que había sucedido y de lo que se podía tratar, abandoné a toda prisa el teatro y me dirigi a mi residencia. Me encontré con los mencionados señores que me dijeron que la señora Cavell había sido condenada a muerte esa misma noche. Al mismo tiempo, me transmitieron un recurso de gracia del Embajador americano, suplicándome que lo apoyara...." ${ }^{51}$.

Brand Whitlock en sus memorias relata que él se enteró de forma indirecta de que la señora Cavell iba a ser ejecutada. Whitlock, enfermo y en cama, avisó a Hugh Gibson para que este avisara a su vez a Villalobar, quien consiguió a ultima hora de la víspera de la ejecución, entrevistarse con Von der Lancken ${ }^{52}$. Según el relato de Whitlock, parece que Von der Lancken no estaba al tanto de lo inminente de la ejecución, y que hizo lo posible para evitarla. Este extremo no ha podido ser confirmado. Lo que queda claro sin embargo, es que Villalobar realizó enormes esfuerzos por evitar la ejecución ${ }^{53}$.

51 B. VON DER LANCKEN, op cit, pp. 204-205.

52 L'Independance Belge, 23 de junio de 1926 y Le Peuple del 22 de junio de 1926.

53 Le XXème Siècle, 22 de junio de 1926. 
Edith Cavell dejó una carta manuscrita, cuya copia se encuentra en el Palacio Real: "Es éste un momento para mi muy triste, al escribiros para despedirme de vosotras - se dirigía a sus antiguas alumnas en Bélgica-, si alguna de vosotras tiene algún perjuicio que reprocharme, ruego que me sea perdonado. Tal vez en ocasiones he sido demasiado severa, pero nunca injusta a propósito, y os he querido mucho, más de lo que imagináis. Mis deseos de felicidad son para todas, tanto las que se fueron, como las que todavía están todavía en la Escuela. Gracias por la gentileza que siempre me habéis demostrado. Vuestra directora, Edith Cavell. Prisión de St. Pilles, 10 de octubre 1915»54.

La señora Cavell fue juzgada por la violación del párrafo 58 del código militar alemán que estipulaba que "cualquier persona, con la intención de ayudar a una potencia hostil o que cause daño a las tropas alemanas o aliadas, es culpable de uno de los crímenes del Párrafo 90 del Código Penal alemán, y será condenada a muerte por traición»55. El crimen establecido en dicho párrafo era el de "conducir soldados al enemigo". Villalobar y el secretario de la legación norteamericana en Bruselas, Hugh Gibson, intentaron convencer a Lancken para que llamara al Cuartel General en Charletville por teléfono y que el caso fuese sometido ante el emperador. Lancken se negó alegando que no podía hacer algo así, dirigiéndose a Villalobar le señaló: «yo no puedo hacer algo así. Yo no soy amigo de mi Soberano como usted es del suyo" ${ }^{56}$.

Lancken finalmente se negó alegando que el Gobernador Militar de Bruselas era la autoridad suprema (Gerichtsherr) en ese tipo de temas y que ni siquiera el Gobernador General tenía el poder de intervenir en ese caso. Tras una acalorada discusión, aceptó despertar al Gobernador Militar, el general Von Sauberweig, para preguntarle si había ratificado la sentencia y si existía alguna oportunidad para la clemencia. Lancken había partido hacía media hora, y a partir de ahi Villalobar, Hugh Gibson junto con Harrach y Falkenhausen debatieron el mejor camino a seguir 57 . Cuando Lancken regresó informó que el Gobernador Militar le había comunicado que había actuado en este caso tras una madura deliberación. Señaló que los crímenes de la Señora Cavell eran de tal gravedad que sólo era posible la pena capital. Lancken comentó que bajo el código penal militar alemán, el Gerichtscheer tenía poder absoluto para aceptar o denegar el recurso de clemencia, y que en este caso, el gobernador lamentaba tener que rechazar la petición de clemencia. Cuando Villalobar y Gibson reabrieron la posibilidad de llamar al emperador por teléfono, Lancken señaló que el asunto había llegado ya demasiado lejos: "ni el Emperador hubiese podido salvarla" ${ }^{58}$.

\footnotetext{
54 AGP. OPC. Caja 37. Carta póstuma de Edith Cavell, en la Prisión de Saint-Gilles. (Bruselas). 10 de octubre de 1915.

${ }^{55}$ Citado en H. GiBson: A journal from our Delegation in Belgium, Garden City, 1917, p. 350.

56 Idem, p. 358.

${ }^{57}$ Ludwig Von Falkenhausen, general alemán nombrado Gobernador General en abril de 1917, y Conde Von Harrach, oficial alemán encargado de la prensa en la Bélgica ocupada.

${ }^{58}$ H. Giason, ob. cit., p. 359.
} 
El representante norteamericano, Whitlock, narra en su diario aquellas dramáticas horas en las que se intentaba salvar la vida de Edith Cavell: "11 de octubre de 1915 (...) Es medianoche, Gibson acaba de llegar con una cara muy pesimista. De Leval y Gibson han ido a buscar a Villlalobar y vieron a Von der Lancken, que dijo que no haría nada, Villalobar estuvo esplendido, habló muy duramente con Von der Lancken, que estaba nerviosísimo (...) ni siquiera quiso recibir mi nota pidiendo clemencia por la pobre mujer (...) estábamos todos abrumados por el horror. 12 de octubre. Estamos todos horrorizados con el destino de la pobre, la valiente, la noble Edith Cavell, la mártir (...) Pude contemplar la totalidad de la escena, conociendo tan bien a aquellos hombres y el lugar, ese frió y falso arrepentimiento mefistofeliano de Von der Lancken, sonriendo con su "Mon Dieu, Mon Dieu!" y su "Je regrette", y Harrach ese bruto y estupido, en su uniforme de húsar, pidiendo una botella de cerveza y diciendo: "Estas discusiones tienen una ventaja... siempre dan sed", luego Villalobar, querido y valiente Villalobar, finalmente enfadándose y diciéndole a Von der Lancken lo estúpidos y brutales que eran, empujándole a la habitación contigua para hablarle, de la que Von der Lancken salió pálido y tembloroso, dirigiéndose a llamar al Gobernador Militar de Bruselas, que no haría nada...."59.

Brand Whitlock recordaba en su autobiografía cómo Villalobar mantuvo una viva discusión a solas con Von der Lancken, la totalidad de la conversación no se conoce, pero Whitlock escuchó a Von der Lancken negándose a hablar más del tema: «Es inútil..."; Villalobar insistió furioso "!Necesito hablarlej»" ${ }^{60}$. A continuación siguió «...diciéndole cosas que hubiese dudado decir en presencia de Harrach, Falkenhausen, y de Leval (...) Lancken se jactaba y se enfadaba, pero permaneció firme en su negativa ${ }^{61}$. Nuestro representante intentaba todo tipo de estrategias para hacer reaccionar a los alemanes, así lo recuerda Brand Whitlock en sus memorias: «...de repente Villalobar gritó: " $\mathrm{Se}$ trata de una mujer por Dios, no se puede fusilar a una mujer así como asíi" El Barón pareció realmente conmovido...»" ${ }^{62}$. Villalobar concluyó de forma dura diciéndole a Von der Lancken: «...jes idiota lo que vais a hacer!, vais a tener otro Lovaina!" ${ }^{63}$. La historia ha condenado a Lancken por no realizar la única llamada que hubiese salvado a Cavell, llamar al emperador. "El único error de Lancken fue no atreverse a llamar al Emperador, quien se encontraba en Spa, y que parece, lamentó mucho la muerte de Cavell, de la cual nadie le advirtió" ${ }^{64}$. Whitlock recuerda haber oído a Villalobar decirle al final a Von der Lancken: «Su sangre permanecerá en vuestra conciencia como lo está la sangre de Lovaina. Von der Lancken comenzó a temblar, se puso pálido y contestó: "Lo sé, estáis en lo cierto pero no puedo hacer nada contra el ejército"»65.

59 A. NEVINS, ob. cit., pp. 217-218.

60 B. WHITLOCK, ob. cit., vol II, pp. 109-110.

61 H. GiBson, ob. cit., p. 360.

62 B. WHITLOCK, ob.cit., pp. 108-109

63 Idem, p. 110. Hacía referencia al brutal incendio de la Universidad de Lovaina que dañó la imagen de Alemania en la Primera Guerra Mundial.

64 La Libre Belgique, 22 de junio de 1926.

65 A. Nevins (ed), ob. cit., p. 221 
Whitlock recordaba en sus memorias el efecto que tuvo el fusilamiento de Cavell: "19 de octubre de 1915 (...) Estamos todos indignados - hasta el mismo Von der Lancken- ya que le dijo a Villalobar que cuando el Káiser supo del asesinato de la señora Cavell, se puso furioso, preguntó todos los detalles al respecto, lanzó órdenes, tomó medidas. Villalobar envió una carta a su Rey, quien telegrafió al Káiser diciendo: "La piedad es la mayor prerrogativa de un soberano". Von der Lancken se enfadó con la actuación de Villalobar. ¡Piedad en un corazón prusiano! ${ }^{66}$.

La sentencia había sido ratificada por el Gobernador Militar y una vez ahí «ni siquiera el mismo Emperador podía hacer ya nada"67. Este hecho, aceptado en el momento como una verdad absoluta, era falso y causó un gran pesar en el emperador. En realidad, el emperador podía haber detenido la ejecución en cualquier momento. Hugh Gibson, quien con Whitlock y Villalobar fue uno de los que más hizo por evitar el trágico desenlace, concluye la parte de sus memorias que dedica a Cavell señalando: «Nuestros esfuerzos eran completamente inútiles, ya que los tres hombres con los que teniamos que tratar, eran tan absolutamente fríos e indiferentes que era imposible conmoverlos con nada de lo que pudiésemos decirles» ${ }^{68}$. Es muy probable que la gestión de Villalobar hubiese tenido éxito de haber contado con un temprano telegrama de Alfonso XIII para reforzar su petición ante las autoridades locales alemanas, también faltó una reacción más rápida y contundente por parte del presidente norteamericano Wilson.

En sus memorias, el Barón Von der Lancken intentó lavar su imagen y la de Alemania por no haber salvado a Edith Cavell. No describe la violenta conversación que tuvo con Villalobar, limitándose a decir que habló con él:

«...Me encontré asi con estos señores que me esperaban en mi casa, les expuse mis sincero lamento, les hice saber que el general Von Sauberweig no se había mostrado nada receptivo a mis objeciones y se había negado a aceptar la petición de clemencia, por lo tanto no habia ya nada que yo pudiese hacer. El Embajador español, Marqués de Villalobar, unido a mí desde hacía muchos años, me habló personalmente y me presionó para telefonear inmediatamente a Charleville -eran en ese momento las doce y media de la noche- para solicitar la intervención del Káiser, propuesta que lamentablemente yo no podía llevar a cabo. No era sólo que mi situación no me lo permitiese, sino que era del todo imposible, por razones puramente prácticas, el obtener en plena noche la comunicación telefónica con el Káiser. Villalobar me dijo afligido: "vuestros enemigos van a hacer de esto un asunto de todos los demonios". Yo debía al menos intentar ante él y su colega americano, llamar a Charleville y preguntar si yo podia todavia hablar con el Káiser. ¿No significaría eso un gran alivio para mí? Yo tenía que tomar una terrible decisión. Naturalmente, lo más simple habría sido desembarazarse de toda esa presión de un asunto, sobre el cual, en realidad, yo no podía tener ninguna influencia. Sin embargo, ¿que sucedería si el Káiser, despertado violentamente, no

66 Idem, p. 222.

67 H. GiBson, ob. cit., p. 359.

68 Idem., p. 360. 
alcanzaba a entender inmediatamente toda la situación?, ¿y sus consejeros responsables le comprometian a rechazar el indulto?, ¿y si los contratiempos materiales hacian que el Káiser pronunciase el indulto con un minuto de retraso? En cualquiera de esas eventualidades, aunque el Káiser no hubiese podido tomar una decisión, yo le veía desbordado delante de sus enemigos, delante del mundo entero, con la responsabilidad exclusiva de la ejecución. Encarnación de lo más odiado de Alemania, se convertiría asi en el asesino, y todo ello porque un general testarudo, insensible a la más mínima noción política, poderoso en su terreno, no hubiese querido ceder y no hubiese al menos pedido una prórroga. La solución más simple para mí, que consistía en liberarme de toda responsabilidad, se convertía así en algo imposible. Yo le hice entender a Villalobar entonces, que de esa forma yo haria recaer toda la responsabilidad de la ejecución sobre el Káiser (...) En la penumbra de la mañana siguiente, la tragedia llegaba a su funesto epílogo. La señora Cavell fue fusilada» ${ }^{69}$.

Edith Cavell demostró una gran entereza ante la ejecución que se avecinaba, finalmente el momento que iba a ser fusilada su resistencia se vino abajo, "cayendo al suelo, desvanecida, a unos veinte metros del paredón». El oficial alemán "desenfundó su revolver de ordenanza, puso su rodilla en tierra, apunto con calma y le disparó un tiro en la cabeza» ${ }^{70}$.

El 30 de mayo de 1919, Villalobar escribió al Conde de Romanones: “...Hace tres dias me visitó sir Francis Villiers, Ministro de la Gran Bretaña en esta Corte, para decirme que su Gobierno había resuelto trasladar a Inglaterra los restos mortales de Edith Cavell, que yacían en los terrenos del Tiro Nacional de esta ciudad y que su Gobierno deseaba fueran enterrados en su lugar natal. Añadiome que anhelaba que la ceremonia fuera presidida con él por el ministro de Estados Unidos y por mi, dado que por enfermedad de éste me había ocupado yo con tanto interés a favor de su infortunada compatriota tratando de salvarla. Creí aceptar desde luego, $y$ en efecto esta mañana se ha celebrado la triste fúnebre ceremonia presidida por las dos hermanas y el cuñado de la difunta enfermera fusilada, una Representación de su Majestad el Rey de los Belgas, la de éste Gobierno y los tres ministros mencionados (...) El duelo se despidió en la estación y asistieron al acto además de los mencionados, todo el cuerpo diplomático en masa y representaciones numerosísimas del Gobierno, del Ejército, de la Banca, la Sociedad, en fin una verdadera manifestación de duelo por la familia y de simpatía y adhesión a la Gran Bretaña (...) Creo inútil añadir la satisfacción que me causó el que la Legación de Su Majestad Británica en esta Corte, diera tan preferente lugar y rodeara de tales consideraciones a la Representación de Su Majestad y a España " ${ }^{71}$.

En su carta al Ministro de Estado, Villalobar relataba el ambiente de Bruselas el 13 de mayo de 1919 cuando se procedió al traslado de los restos de la heroína a

69 B. VON DER LANCKEN, ob. cit., pp. 210-211.

70 AGP. OPC. Caja 37. Recortes de Prensa descabezados que se encuentran, anexos al Expediente. Los mismos están fechados el 19 y 20 de octubre de 1915.

71 AMAE. 3017 . Despacho n. ${ }^{\circ} 204$, duplicado. 
su país natal: «Rodeaban al fúnebre armón, dándole escolta, fuerzas británicas, americanas y belgas, atravesando así, desde el Tiro Nacional, las arterias principales de la ciudad, donde la mayor parte de las casas izaron banderas a media asta con crespones y otros signos de duelo. La muchedumbre se apiñaba por las calles del tránsito, contenida por la policía.... ${ }^{72}$.

Arthur Zimmerman, ministro de Asuntos Exteriores alemán, dio su particular versión del fusilamiento de Edith Cavell a la prensa. La opinión de Zimmerman era que la ejecución de Cavell era lamentable pero necesaria y justa ${ }^{73}$. La siguiente nota fue dada a la prensa alemana por el ministro Zimmerman: «Ha sido una pena que la señora Cavell tuviese que ser ejecutada, pero era necesario. Fue juzgada justamente. Esperamos que no tenga que haber nuevas ejecuciones. Deduzco de la prensa inglesa y americana que el fusilamiento de una mujer inglesa y la condena de otras mujeres en Bruselas bajo cargos de traición, ha causado una profunda impresión, y se nos juzga por ello. Indudablemente ha sido algo terrible que haya sido ejecutada, pero consideren que sucedería, si un Estado, en especial estando éste en guerra, dejase pasar crímenes contra sus soldados, sólo por el hecho de haber sido cometidos por mujeres... Innumerables soldados belgas, franceses e ingleses están luchando de nuevo en las filas de los Aliados, todos ellos deben su escape a las actividades del grupo que ha sido declarado culpable, y cuya cabeza era la señora Cavell. Sólo la severidad más absoluta podía terminar con ese tipo de actividades, realizadas ante los propios ojos de nuestras autoridades, y un gobierno que no tome las medidas más duras, sería culpable de ignorar las obligaciones más elementales para la seguridad de su propio ejército.... ${ }^{74}$.

El 7 de mayo de 1919, el día en que los delegados alemanes en Versalles, recibían el proyecto del tratado de paz, el cuerpo de Edith Cavell fue trasladado a Inglaterra a bordo del destructor Rowena. Ocho días después tenía lugar el funeral en la Abadía de Westminster, en la que se congregó una multitud de ingleses que querían presentar sus respetos a la heroína nacional. "Durante el paso de la enfermera Edith Cavell a través de Londres", informaba el periódico The Times, "una maravillosa parálisis recorría las calles que a mediodía son normalmente bulliciosas" 75 . En su honor Canadá dio el nombre de Mount Cavell a una de las montañas de las Rocosas. En Londres, su estatua fue situada al norte de Trafalgar Square. Durante meses, hombres hacían guardia cerca de ella para asegurarse de que todo el que pasara por delante se quitara el sombrero ${ }^{76}$. En 1926 la revista The Spectator recordaba los esfuerzos de Villalobar por salvar a la heroica enfermera

72 AMAE. 3055/6 Carta del Marqués de Villalobar al Ministro de Estado de 13 de mayo de 1919.

${ }_{73}$ Zimmerman se ganaría un lugar en la historia por el telegrama que lleva su nombre y que fue uno de los motivos de la entrada en guerra de Estados Unidos. Véase: B. Tuchman, The Zimmerman Telegram, Nueva York, 1994.

${ }_{74}$ Source Records of the Great War, vol III, Charles F. Horne (ed.), 1923.

75 The Times, 7 de mayo de 1919.

${ }^{76}$ M. GILBERT, The First Wolrd War, Nueva York, 1996, p. 514. 
inglesa: «hace ya unos meses que falleció el Marqués de Villalobar, que era el Embajador de España en Bélgica durante la guerra... sus gigantescos esfuerzos por salvar a Edith Cavell no deben ser injustamente olvidados por nosotros ${ }^{77}$.

\section{EL BURGOMAESTRE ADOLPHE MAX}

La figura del burgomaestre Adolphe Max fue una de las más respetadas y queridas en la Bélgica ocupada junto con las del Marqués de Villalobar y Brand Whitlock. El burgomaestre tuvo un papel destacado, manteniendo el honor de la población belga y dificultando todo lo que pudo la acción del odiado invasor alemán. Desde los primeros días de la ocupación alemana, Adolphe Max había intentado oponerse a las órdenes alemanas. En primer lugar, negándose a bajar la bandera belga de las casas de Bruselas y, posteriormente, negándose a pagar las sumas impuestas por los alemanes a la población belga para mantener su esfuerzo de guerra $^{78}$.

La historia se propagó enseguida por todo el país, Adolphe Max se convirtió en el símbolo de la resistencia. Toda la ciudad admiraba la valentía de su burgomaestre, que comenzó a ser como recordaba Brand Whitlock: «...popular, demasiado popular tal vez "79. El día 24 de septiembre de 1914, el burgomaestre Adolphe Max y el general Von Jarotsky mantuvieron conversaciones sobre los cincuenta millones de francos que los alemanes exigían a la ciudad. Adolphe Max declaró, como lo había hecho antes a Villalobar y a Brand Whitlock, que la ciudad no podía satisfacer semejante cifra. Sin embargo, señaló que intentaría conseguir rápidamente un millón y medio e intentó que Von Jarotzky redujese la cifra total a veinte millones. Von Jarotsky señaló que él no tenía ese poder, pero que intentaría utilizar su influencia entre sus superiores para reducir las exigencias. El general también acordó con el burgomaestre que no se realizarían más requisas de comida ni de provisiones por ocho días.

Adolphe Max consiguió un respiro de 30 días en el pago de 45 millones de francos. Se había decidido entre los delegados de las diversas Comunas de la Agglomération Bruxellois, que la Comuna de Bruselas pagaría 20 millones y el resto se dividiría entre la población. La ciudad, es decir, la Comuna de Bruselas realizó sus pagos regularmente, hasta que el 30 de septiembre se comprobó que a la ciudad le quedaban todavía cuatro millones de francos para pagar. Lo que había sucedido es que las Comunas no habían sido capaces de recaudar los treinta millones y que la Comuna de Bruselas no poseía los fondos necesarios para cubrir la parte de las otras.

77 The Spectator, 11 de Septiembre de 1926.

78 AFV. 11/1914. Carta de Villalobar al Marqués de Estado sobre la situación general en la Bélgica ocupada.

${ }_{79}$ B. WHITLOCK, ob. cit., p. 303. 
El día 27, dos días después del acuerdo al que habían llegado Von Jarotsky y Adolphe Max, un oficial alemán se presentó al burgomaestre exigiendo provisiones para sus tropas y caballos. Adolphe Max recordó al oficial alemán el acuerdo al que había llegado con Von Jarotsky. El general alemán le contestó que él no se sentía vinculado por tal acuerdo. El conflicto con las autoridades de ocupación era así inevitable. Finalmente, los alemanes enviaron al comandante de la Plaza, Bayer, con cuatro soldados para detener al burgomaestre ${ }^{80}$.

Las palabras de Adolphe Max en el momento de su detención dan testimonio de su dignidad y valor frente a los alemanes: “...lamento no poder seguir realizando mis funciones hasta el final. Sin embargo, tengo la satisfacción de haber cumplido con mi deber. Ustedes me dijeron desde el principio que deseaban evitar problemas y dificultades en Bruselas, yo conozco el temperamento de mi gente mejor que ustedes, y de no haberme interpuesto entre ustedes y la población de Bruselas, hubiésemos tenido un baño de sangre. Por lo tanto no me puedo arrepentir de haber hecho lo que hice. Me alegro también de que hasta este momento, cuando mi autoridad llega a su fin, hayamos tenido paz en este lugar. Ahora que me han hecho prisionero, encuentro cierto alivio en el hecho de que yo ya no seré responsable de lo que ocurra a partir de ahora" ${ }^{81}$. Brand Whitlock escribia en sus memorias: “...cuando regresé el día 26 a mi legación, Villalobar se encontraba allí esperándome. Conversamos un poco sobre la situación cuando el señor Jacquemain fue anunciado: ¡Malas noticias! exclamó mientras entraba en la habitación. ¡Max ha sido detenido! „82. Villalobar y Whitlock decidieron ir a ver al general Von Lüttwitz. A la puerta del antiguo Ministerio de Asuntos Exteriores los centinelas les preguntaron irónicamente para qué querían ver al general. Villalobar, recuerda Whitlock, se puso furioso lanzándoles un «iMonsieur!» que dejó pálidos a los centinelas ${ }^{83}$.

Villalobar, una vez que era evidente que los alemanes ya no soltarían al burgomaestre Adolphe Max, hizo todo lo posible por mejorar su suerte. El 7 de abril de 1917 el secretario particular del rey Alfonso XIII escribía a Villalobar comentándole las gestiones realizadas a favor de Adolphe Max: «Mi querido amigo y compañero: De orden de S.M. El Rey nuestro Augusto Señor, me apresuro a manifestarle que nuevamente se ha escrito al Embajador en Berlín para que con el mayor interés procure alcanzar de las Autoridades alemanas que se mejore la suerte del Burgomaestre de Bruselas Adolphe Max, por quien usted tanto se interesa..." ${ }^{84}$.

El mismo Adolphe Max se había quejado en una carta manuscrita al embajador de España en Berlín, Polo de Bernabé, del trato que recibía de los alemanes. La Oficina Pro Captivis del Palacio Real se puso inmediatamente en acción para

80 Idem., p. 302.

81 Idem., p. 303.

82 Idem., p. 307

83 Idem., p. 308.

84 AFV. 24/1917. Carta Personal del Secretario Particular de Alfonso XIII Emilio de Torres a Villalobar. 
mejorar la situación del famoso burgomaestre y evitar que se tomaran represalias en contra de su persona. A través del embajador en Berlín, así como desde Bruselas con Villalobar, se hizo un seguimiento de la situación del alcalde para evitar que en su pugna con las autoridades del campamento, el burgomaestre pudiese ser castigado de forma severa.

En enero de 1917 se decidió enviar al capitán médico, delegado de España en Alemania, a visitar a Adolphe Max y observar de cerca su situación personal. El burgomaestre habló de los abusos a los que era sometido por los alemanes en el campo, como la restricción de correo, "preguntado por su estado de salud, me responde que se encuentra bien, aunque con las molestias morales naturales, consecutivas al dilatado espacio de tiempo que de prisionero lleva..." ${ }^{85}$. Adolphe Max manifestó su gran agradecimiento a España por servir de garante de su estado físico y moral. El Barón Grénier, ministro plenipotenciario y enviado extraordinario belga en Madrid, presionaba a la Oficina Pro Captivis para mejorar la suerte de su burgomaestre. Según Grénier, parte de los abusos y maltratos que recibía Adolphe Max, provenía del hecho de haberse quejado al embajador de España en Berlín: “...M. Max avait été l'objet de mesures de rigeur pour avoir osé adresser des plaintes à l'Ambassade d'Espagne..." "

Las autoridades alemanas insistian en que la conducta de Adolphe Max en el campo de prisioneros era intolerable: «...El burgomaestre Max hubo de ser castigado por graves transgresiones contra el orden del campamento -por haber rehusado tenazmente a tomar parte en las listas prescritas para los prisioneroscon arresto en cuarto de 8 y 14 días... en interés de la disciplina del campamento, ha sido trasladado de nuevo a la prisión militar de Berlín...."87.

Según un informe de delegados españoles en Berlín: «...Max está castigado con prisión y no está comprendido en el Convenio germano-belga relativo a la liberación de los prisioneros civiles reciprocos. Por lo tanto no puede permitírsele el regreso a Bélgica o la liberación a un país neutral, prescindiendo de que motivos militares se oponen a ello' ${ }^{88}$. Sin embargo, y pese a lo anterior, las presiones internacionales y muy especialmente la española no consiguieron que Alemania liberase al ilustre burgomaestre belga. Finalmente, Adolphe Max fue liberado tras el fin de la guerra. Esta importante noticia era comunicada por el Marqués de Alhucemas, entonces ministro de Estado al Barón van der Elst, Ministro Plenipotenciario de Bélgica en España: «...el alcalde señor Max ha sido puesto en libertad señalándose por ahora residencia en Goslar cerca de Brunswick...»" ${ }^{89}$. La noticia causó

B5 Citado en N. AguirRe de CárCer, La Neutralidad de España durante la Primera Guerra Mundial, (1914-1918). I Bélgica. Madrid, 1995, pp. 271-272.

86 AFV. 3/1917. Copia de la carta del Barón Grénier al Ministro de Estado de 22 de abril de 1917.

87 AFV. 3/1917.Expediente del Burgomaestre Adolphe Max, Anexo al Despacho número 2.535, de 6 de junio de 1918 de la Embajada en Berlín.

88 Citado en A. AguiRRE DE CARCER, ob. cit. Documento número 209.

89 AFV, 6/1918. Expediente del Burgomaestre Adolphe Max. Carta del Marqués de Alhucemas al Barón van der Elst, de 29 de octubre de 1918. 
una gran alegría en Bélgica y las muestras de agradecimiento a la labor de España no se hicieron esperar. El mismo Burgomaestre Adophe Max escribió al Rey Alfonso XIII: "Profondément touché de l'aimable télégramme de Votre Majesté, je la prie d'agréer mes respectueux remerciements ainsi que la nouvelle expression de ma gratitude pour l'intérêt qu'elle a daigné me témoigner pendant ma captivité en Allemagne" ${ }^{90}$.

\section{EL CASO CARTON DE WIART}

El caso Carton de Wiart tuvo una enorme repercusión desde los primeros días de la Gran Guerra y fue uno en los que más empeño puso el Marqués de Villalobar. La señora Carton de Wiart, era la mujer del ministro de Justicia belga. Cuando el gobierno belga abandonó Bruselas, ella decidió quedarse en la capital en compañía de sus seis hijos. Desde el primer momento la señora Carton de Wiart se negó a cumplir la ley marcial impuesta por el invasor. El día 20 de mayo de 1915 fue arrestada y conducida ante un tribunal constituido en el Senado belga. La señora Carton de Wiart fue condenada a tres meses de prisión. La sentencia se fundaba en que la esposa del ministro de Justicia reconocía haber hecho todo lo posible para que se proporcionara a algunas familias en Bélgica noticias de familiares que servian en el ejército, algo totalmente prohibido por los alemanes. Reconocía también haber distribuido ejemplares de la famosa carta pastoral del cardenal Mercier sobre «Patriotismo y abnegación». La señora Carton de Wiart fue enviada a Berlín ingresando en la prisión de Moabit ${ }^{91}$.

Todos los esfuerzos que se hicieron para obtener su libertad fueron infructuosos, tanto del Papa como del presidente de Estados Unidos, Woodrow Wilson. Las gestiones del Marqués de Villalobar, ayudado por el empeño personal del Rey Alfonso XIII, tuvieron mejor fortuna, consiguiendo que el gobierno alemán resolviera complacer al rey Alfonso XIII y a su representante, permitiéndole elegir su residencia en cualquier lugar de Europa a excepción de Bélgica, cuestión en la que el gobernador alemán Von Bissing se mostró inflexible ${ }^{92}$. El 4 de septiembre de 1915, despedida por nuestro embajador en Berlín, Polo de Bernabé, la señora Carton de Wiart abandonó Alemania y se internó en Suiza, donde encontró a todos sus hijos. Las gestiones del Rey Alfonso XIII y el Marqués de Villalobar habían conseguido triunfar donde todas las otras naciones habian fracasado.

90 AFV. 19/1918. Carta del Burgomaestre Adolphe Max al Rey Alfonso XIII, de 25 de noviembre de 1918.

91 AFV. 2/1915. Documentación relativa al caso de la señora Carton de Wiart. Véase también J. CoRtes-Cavanillas, Alfonso XIII y la Guerra del 14, pp. 192-193.

92 AFV. 2/1915. Documentación relativa al caso de la señora Carton de Wiart. 


\section{CONCLUSIÓN}

La labor de mediación del Marqués de Villalobar, de la que he destacado tan sólo algunos aspectos fue muy reconocida en Bélgica, como se reflejó en los medios de prensa tras su fallecimiento en Bruselas. «La actuación de nuestro Embajador en Bélgica durante la Guerra Europea, en el periodo de la ocupación alemana, no sólo como representante del Gobierno español, sino como depositario de la confianza de los paises beligerantes, que encontraron en él al más cabal interprete del derecho y la justicia, constituye una hermosa página de la diplomacia española. Como delegado de la Oficina Pro Captivis establecida en el Palacio por S.M. El Rey, el marqués de Villalobar realizó una activa e inteligente labor que mereció la gratitud de todos los gobiernos interesados. En Bélgica se le profesaba gran cariño y la gratitud del Estado y del pueblo se tradujo en honrosos homenajes»" ${ }^{93}$. «De tal forma se había compenetrado con la honrosa misión que se le confiara, que bien pronto dejó de ser en Bélgica España, el país protector: lo era personalmente el Marqués de Villalobar "94.

Villalobar falleció de una peritonitis el viernes 9 de julio de 1926 a los 60 años. El diario La Época describía así la muerte de Villalobar: «...El Marqués de Villalobar se encontraba enfermo desde hace algún tiempo, una de las últimas veces que estuvo en Madrid padeció un ataque de apendicitis y hubiera querido someterse entonces a la operación que ahora le ha sido practicada. Los deberes de su cargo de los que era muy celoso cumplidor, le obligaron a marchar a Bruselas, demorando para más adelante la intervención quirúrgica. Al someterse a ella hace pocos días no le ha acompañado la fortuna y la muerte le ha arrebatado a nuestra patria un lealísimo servidor" ${ }^{95}$. "...Con el Marqués de Villalobar desaparece una gran figura de la diplomacia española, una figura que durante la espantosa tragedia de la guerra mundial, supo aureolarse con todos los prestigios altamente humanos de la dignidad y del bien"\$6. Al funeral de Villalobar acudieron "miles de belgas que apesadumbrados venían a rendir por ultima vez su gratitud a éste gran benefactor de Bélgica..." " ${ }^{97}$. "Si en sus relaciones diplomáticas fueron sus cualidades salientes la energía y la habilidad, en su trato con los que a su amparo se acogían empleó siempre la amabilidad más exquisita...y cuando las victimas, los perseguidos, los que reclamaban su protección eran españoles, el Embajador convertíase en un servidor abnegado que no reparaba en molestias ni sacrificios para el alivio y la liberación de los demandantes" ${ }^{98}$.

El propio rey Alberto I se personó en la embajada española, a testimoniar su gran pesar ${ }^{99}$. El entierro, cuatro días después, fue seguido por una multitudinaria

${ }^{93}$ El Imparcial, 10 de julio de 1926.

94 La Provincia, 1 de agosto de 1926.

95 La Época, sábado, 10 de julio de 1926.

96 La Esfera. Número 654. 17 de julio de 1926.

${ }^{97}$ Dernières Nouvelles. Bruselas, 13 de julio de 1926.

98 El Diario de Barcelona, 23 de julio de 1928.

99 AFV. Diversos recortes de periódicos que se encuentran en el expediente del fallecimiento del Marqués de Villalobar. 
manifestación de dolor ${ }^{100}$. Más de cien coronas fueron enviadas a sus exequias ${ }^{101}$. Una brigada de infantería, del ejército belga, cubría el trayecto hasta la Gare du Midi donde fue trasladado su féretro hasta Madrid ${ }^{102}$. El Marqués de Villalobar está enterrado en la Sacramental madrileña de San Isidro ${ }^{103}$.

100 Entrevista Personal con Carlos SaAvedra, hijo del marqués de Villalobar (fallecido en mayo de 2004), diciembre de 2003.

101 AMAE. Expedientes Personales, 276/19.786.

102 El Diario de Barcelona de 23 de julio de 1928.

103 AMAE. Expedientes Personales, 276/19.786. 